\title{
Design and simulation research of micro-source inverter comprehensive test device in microgrid
}

\author{
Zhong-Lin Zhang ${ }^{1}$,Tao Wang ${ }^{1}$, Hong Bai ${ }^{1}$, Bao-Guo Li ${ }^{2}$, Kai Zhao $^{2}$, Yu Zhang $^{\dagger}$ \\ 1. Jinzhou City Power Supply Company \\ State Grid Liaoning Electric Power Co. Ltd. \\ No. 20, Jiefang Street, Guta District, Jinzhou 121000, P.R. China \\ zhangyu.gy@foxmail.com \\ 2. Department of Electrical Engineering \\ Liaoning University of Technology
}

No. 169, Shiying Street, Guta District, Jinzhou, 121001, P. R. China

\begin{abstract}
Design scheme of comprehensive testing device is given to test the performance of ongrid operation and off-grid operation of micro source inverter in micro-grid. In order to realize zero steady-state error tracking of analog signal, parallel composite control strategy of PI and repetitive control is adopted in the pre-stage simulation of the device, which includes the test control mode of grid connection operation and the test control mode of the islanded operation. The pre-stage load and power voltage are accurate and have a good dynamic performance by simulation. Meanwhile, it also verified the feasibility and rationality of this project.
\end{abstract}

Keywords: Micro-source inverter; Comprehensive test; Repetitive control; zero steadystate error track; PI and repetitive control

\section{Introduction}

With the rise of microgrid technology, microgrid as one of the effective ways of using distributed power supply, which is also an important component of smartgrid[1]. In the AC microgrid, micro source inverter is the core of energy transmission and operation control device, its various aspects performance is closely related to the overall performance of the AC microgrid. In actual operation, there are two kinds of micro source inverter operation mode, namely island operation test and parallel operation test, so it needs island operation test and parallel operation test to get a comprehensive evaluation of its overall performance. In the national standard "off-grid wind power, solar power generation system with inverter technology standard" [2] and the national energy bureau released industry standard "grid-connected photovoltaic inverter specification"[3], the micro source island operation of the inverter and parallel operation is given detailed test standard. 
This research on island operation of the inverter is so deep in current situation, and simulation load test needs to simulate linear and nonlinear load, simulate dynamic load of motor and rectifier load [4-6], only literature [7] to test the parallel inverter are studied, because this design is aimed at $35 \mathrm{kV}-6 \mathrm{MW}$ wind turbines converter parallel test, the test device of large capacity and high voltage is not suitable for small capacity of converter test.

In order to combine microgrid of micro source inverter in laboratory and the implementation of the comprehensive test, this paper presents a comprehensive test device design, which is elaborated the islands of the integrated control of operation and parallel operation test plan in detail. Topological structure is relatively simple, it can accurately simulate all kinds of load characteristic and also won't affect the stability of grid, and the test cost is greatly reduced.

\section{System Structure}

Comprehensive test device structure is shown as in Fig. 1, overall structure is divided into three parts:

(1) Pre-stage is full-bridge voltage-type PWM converter to facilitate the control of load required for simulated islanding test and grid conditions (voltage deviation and fluctuation, frequency deviation and fluctuation, voltage imbalance and fault voltage) for grid-connected test.

(2) Mid-stage is DC link, the main function is to maintain DC voltage filtering and active power balance between pre-stage and post-stage.

(3) Post-stage is three-phase half-bridge PWM converter with voltage-type, and it can finish simulation of nonlinear load characteristics, grid voltage fluctuations and imbalance.

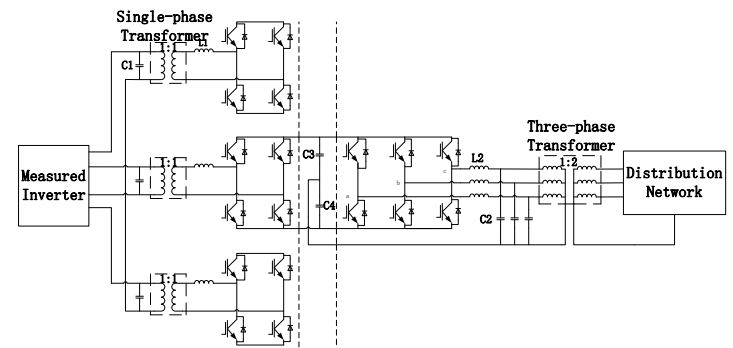

Fig. 1. Structure diagram of comprehensive test device

\section{Design of Pre-stage Control System}

Pre-stage control of test device is divided islanding test and grid operation test, control strategy of two models is designed respectively as follow. 


\subsection{Island running test}

During island running test, single-current-loop control strategy is adopted, and control structure of one phase is shown in Fig.2.

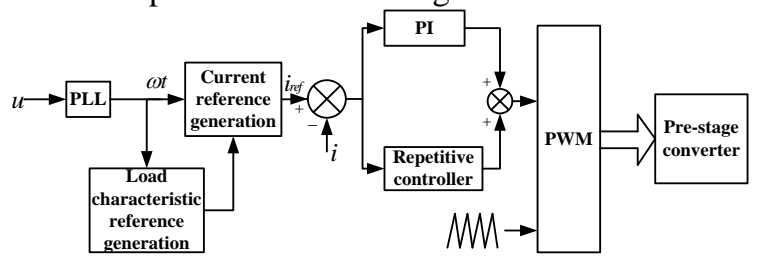

Fig. 2. Control block diagram of pre-island operation test

Where $u, i, i_{\text {ref }}$ respectively is inverter output voltage, output current, output current setting value.

(1) Generation method of inverter output current setting value is different with varies characteristic of analog load. For analog linear load characteristics, inverter output current can be expressed as:

$$
\left\{\begin{array}{l}
i_{\mathrm{a}}=\mathrm{A} \sin (\omega t+\theta) \\
i_{\mathrm{b}}=\mathrm{A} \sin \left(\omega t+\theta+120^{\circ}\right) \\
i_{\mathrm{c}}=\mathrm{A} \sin \left(\omega t+\theta+240^{\circ}\right)
\end{array}\right.
$$

On the basis of inverter output voltage, analog load impedance $\mathrm{Z}$ of each phase can be expressed as follow:

$$
Z_{\mathrm{a}}=Z_{\mathrm{b}}=Z_{\mathrm{c}}=Z=R+\mathrm{j}\left(\omega L-\frac{1}{\omega C}\right)
$$

Amplitude A and phase $\theta$ of output reference current are obtained,

$$
\left\{\begin{array}{l}
\mathrm{A}=\frac{U_{\mathrm{m}}}{|Z|} \\
\theta=\arctan \frac{\omega L-\frac{1}{\omega C}}{R}
\end{array}\right.
$$

Where Um is the maximum value of output voltage, value of $\mathrm{Z}$ can be calculated by $\mathrm{R}, \mathrm{L}, \mathrm{C}$.

(2) Design of Controller

PI + repetitive control of parallel composite control strategy is adopted in prestage controller of device. The main purpose of controller is to realize the zero steady-state error track and good dynamic performance of nonlinear load simulation control instruction. Structure of controller is shown in Fig.3. 


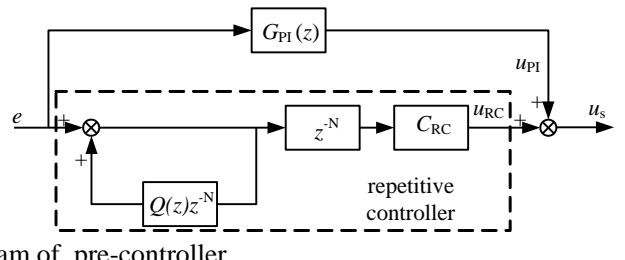

Fig. 3. Structure diagram of pre-controller

Here,e is error of inverter output current, combining $u_{P I}$ of PI controller and $u_{R C}$ of repetition controller to obtain control signal $u_{s}$. In repetitive controller structure, $Z^{-\mathrm{N}}$ stands for periodic delay link, $\mathrm{N}$ is number of frequency cycle sampling. $Q(z)$ represents transfer function of zero-phase-shift filter, purpose of $\mathrm{Q}(\mathrm{z})$ is to improve system stability, system can input ideal signal without static error tracking when $\mathrm{Q}(\mathrm{z})=1$, but in this case, system is in a critical stable state. Usually $\mathrm{Q}(\mathrm{z})$ is less than 1 constant. To ensure steady state margin and whole dynamic performance of controller, Therefore, $Q(z)=0.3$ in this design. $C_{R C}$ is repetitive control gain, where $\mathrm{C}_{\mathrm{RC}}=0.5$. $\mathrm{G}_{\mathrm{PI}}(\mathrm{z})$ is transfer function of PI controller as follow.

$$
G_{\mathrm{PI}}(z)=\frac{\left(k_{\mathrm{P}}+k_{\mathrm{I}}\right) z-k_{\mathrm{P}}}{z-1}
$$

Here, $\mathrm{k}_{\mathrm{p}}$ is proportion coefficient, $\mathrm{k}_{\mathrm{I}}$ is integral coefficient.

\subsection{Grid parallel operation test}

Every phase of this three-phase electricity use the same control structure, and the control structure of single phase is shown in the Fig. 4.

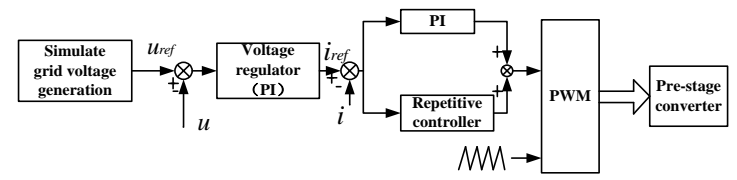

Fig. 4. The control block diagram of the test in preceding stage paralleling operation In Fig. $4, \mathrm{u}$ and $\mathrm{u}_{\mathrm{ref}}$ are grid voltage of pre-stage AC side of the simulation and its reference respectively, $\mathrm{i}_{\text {ref }}$ and $\mathrm{i}$ are current of pre-stage AC side and its reference. Current-loop controller is also current-loop of island operational testing, i.e. PI+ repetitive control compound controller, outer voltage-loop uses PI controller.

\section{Design of Post-stage Control System}

Control strategy of two DC-side capacitances voltage controlled respectively is used for voltage control loop of post-stage control system, which can eliminate the influence of uneven distribution of two DC-side capacitances voltage and 
further improve dynamic response of system. Whole post-stage converter control structure is shown in Fig. 5.

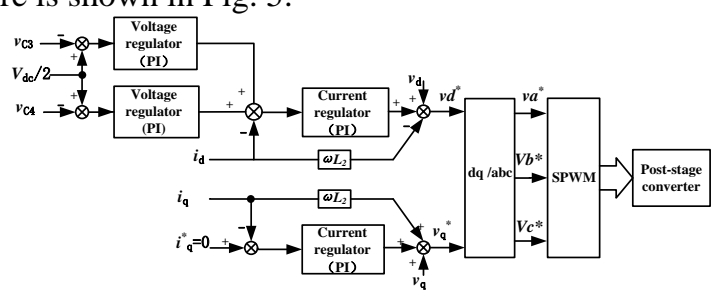

Fig. 5. Structure diagram of post-stage converter control

\section{Simulation Analysis}

\subsection{Test simulation of isolated island operation}

(1) Linear load simulation

When test the measured inverter of isolated island operation, simulation waveform about a phase voltage and current of linear load characteristic simulation shows in Fig. $6, \mathrm{t}=0 \sim 0.15 \mathrm{~s}$, simulation of pure resistor load, set $\mathrm{R}=29 \Omega, \mathrm{t}=0.15 \sim 0.3 \mathrm{~s}$, simulation of resistor-inductance load, set $\mathrm{t}=0.3 \sim 0.45 \mathrm{~s}$, $\mathrm{L}=1.34 \mathrm{H}, \mathrm{R}=20.5 \Omega$, simulation of resistor-capacitive load, set $\mathrm{R}=41 \Omega, \mathrm{C}=1.89 \mu \mathrm{F}$. THD of FFT analysis about simulated load current waveform maximum is $0.09 \%$, and results of simulation indicates that dynamic response is good.

The measured inverter output of active and reactive power shows in Fig. 6. From the Fig6. ,wave form can be seen that as pre-stage current loop is used PI + repetitive control in parallel, there is an error after $0.02 \mathrm{~s}$ at $0 \mathrm{~s}, 0.15 \mathrm{~s}$ and $0.3 \mathrm{~s}$, and after $0.02 \mathrm{~s}$, the error is within the allowable range, it reflects that dynamic response of the control system is good.

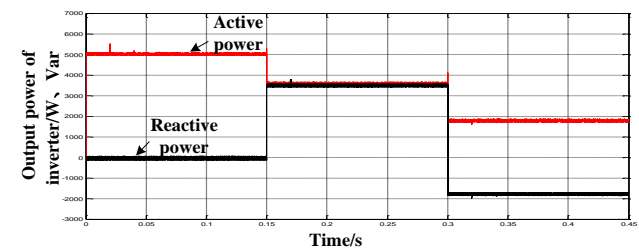

Fig. 6. Simulate linear load characteristics of measured inverter output power

When device simulate linear load characteristics, post-stage simulation waveform of grid-connect current and power are shown in Fig. 7,8. When device runs, grid-connected power increase slowly, and don't impact grid. FFT analysis of grid-connected current waveform shows that THD maximum is $1.72 \%$, harmonic component meets grid-connected standard, and post-stage gridconnect power factor reach $99 \%$. 


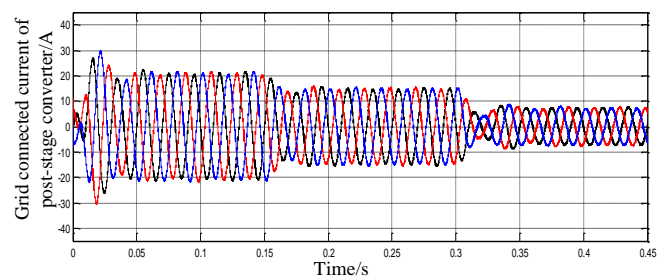

Fig. 7. Analog linear load characteristics of the latter grid-connect current waveform

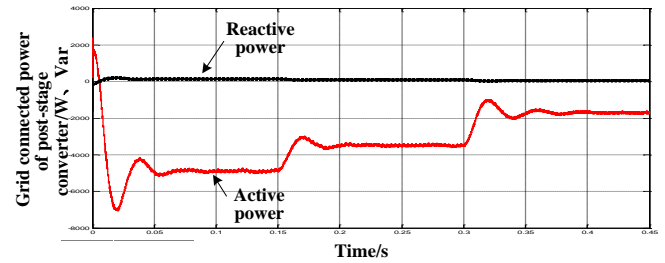

Fig.8.Simulation wave form of linear load characteristics of the latter grid-connect power

(2) Nonlinear Load Simulation

A-phase output current waveform and nonlinear load instruction current waveform are shown as Fig. 9. Static error tracking is achieved by PI+ repetitive control. Grid-connected current waveform is shown in Fig. 10, FFT analysis of the THD is $1.80 \%$, harmonic component meets grid-connected standards.

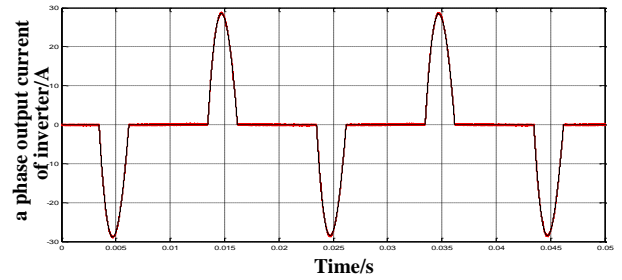

Fig. 9. Simulation waveform about measured inverter output current of nonlinear load characteristic simulation

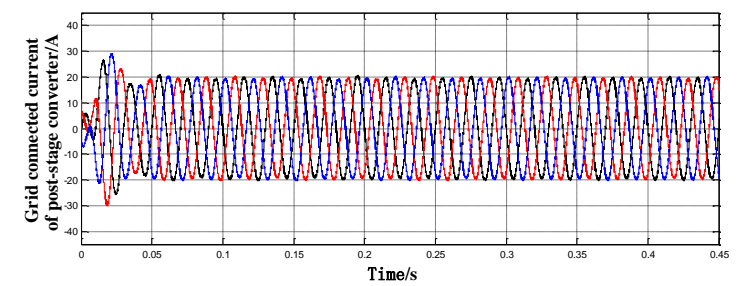

Fig. 10. Simulation waveform about the latter grid-connect current of nonlinear load characteristic simulation

\subsection{Test and simulation of grid-connected operation}

Simulating three-phase unbalanced voltage, voltage amplitude of each phase is set based on unbalance of device. Fig.11 shows unbalanced voltage's waveform of AC side, where three-phase voltage amplitude are $279.9 \mathrm{~V}, 311 \mathrm{~V}, 342.1 \mathrm{~V}$ respectively, the maximum THD of each phase voltage is $0.03 \%$. 


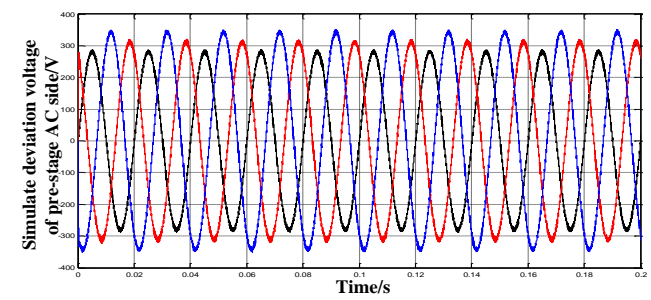

Fig. 11. Simulated unbalanced voltage waveform on the AC side of the former stage when the grid testing

\section{Conclusion}

A comprehensive testing device is designed to test performance of on grid operation and off grid operation of micro source inverter in microgrid. The device of pre-stage realize zero steady-voltage and frequency of varies condition(including voltage deviation, frequency deviation, voltage fluctuation, and voltage unbalance), in addition, simulation load and grid voltage is adjustable continuously. The feasibility and correctness of scheme is verified by the simulation on MATLAB/SIMULINK platform. This scheme has some significance for the test of small capacity grid-connected converter and comprehensive control mode of power electronic devices.

\section{References}

1. X.F. Yang, J. Su, Z.P. Lv, et al. Overview on Micro-grid Technology[J]. Proceedings of the CSEE,2014,34(1):57-70.

2. GB/T 20321.1-2006, Inverter of wind and solar energy supply power system for off-grid[S].

3. NB/T 32004-2013, Technical specification of grid-connected PV inverter[S]

4. Q.J. Huang, M.C Su, X.D. Zou, et al. Design of Power Electronic Load System Simulating Motor Port Characteristics[J].Automation of Electric Power System,2014,38(3):71-77.

5. C.X. Huang. Research on Critical Techology of the Single-phase Power Electronics Load[D]. Degree of Doctor of Huazhong University of Science \& Technology,2012.

6. L. Sang, X.H. Xu, Z.M. Li, et al. Design of simulation system for nonlinear load disturbance[J] .Electrical measure \& Instrumentation.2013, 50(8): 103107.

7. Y.F. Li, Y. Wu, J.L. Wu, et al. Design and Implementation of a Distributed Generation Grid-Connected Converter Testing Device[J]. Transactions of China Electrotechnical Society,2015, 30(3):115-122. 